\title{
Matrine ameliorates the inflammatory response and lipid metabolism in vascular smooth muscle cells through the NF-кB pathway
}

\author{
GUANGLEI WANG $^{1 *}$, CHENGYU JI ${ }^{2 *}$, CHUNLING WANG ${ }^{3}$, \\ ZHONGHUI LIU ${ }^{1}$, AIZHONG QU ${ }^{4}$ and HUAIXIN WANG ${ }^{1}$ \\ ${ }^{1}$ Department of Emergency Medicine, Yidu Central Hospital of Weifang, Weifang, Shandong 262500; \\ Departments of ${ }^{2}$ Cardiology and ${ }^{3}$ Stomatology, Linqu People's Hospital, Weifang, Shandong 262600; \\ ${ }^{4}$ Hematology Department, Weifang Yidu Central Hospital, Weifang, Shandong 262500, P.R. China
}

Received June 4, 2020; Accepted April 19, 2021

DOI: 10.3892/etm.2021.10744

\begin{abstract}
Atherosclerosis is a chronic inflammatory disease associated with inflammatory responses and the uncontrolled proliferation and excessive apoptosis of vascular smooth muscle cells. However, the effects of matrine on the inflammatory response, abnormal lipid metabolism and cell proliferation and apoptosis marker proteins in human aortic vascular smooth muscle cells (HAVSMCs) have not been elucidated. Therefore, the present study aimed to investigate the effect of matrine on an in vitro model of atherosclerosis using HAVSMCs. The HAVSMCs were divided into normal, model and matrine groups. The model group was treated with oxidized low-density lipoprotein (oxLDL), the matrine group was treated with oxLDL and matrine and the normal group was treated with physiological saline. Total cholesterol (TC), free cholesterol (FC) and cholesterol ester (CE) levels were measured in the cell supernatant. In addition, the relative mRNA levels of inflammatory factors were quantified using reverse transcription-quantitative PCR, and the cell proliferation and apoptosis rates were evaluated using Cell Counting Kit-8 and flow cytometry assays, respectively. The expression levels of proteins associated with proliferation and apoptosis were also determined using western blotting. The levels of TC, FC and CE and the mRNA levels of IL-1 $\beta$, IL-6, and TNF- $\alpha$ in the matrine group were lower than those in the model group, but higher than those in the normal group. After 48 and 96 h of treatment, the cell proliferation and apoptotic
\end{abstract}

Correspondence to: Dr Huaixin Wang, Department of Emergency Medicine, Yidu Central Hospital of Weifang, 4138 Linglongshan South Road, Weifang, Shandong 262500, P.R. China

E-mail:whxinwan@163.com

${ }^{*}$ Contributed equally

Key words: matrine, NF-кB pathway, human aortic vascular smooth muscle cells, inflammatory response rates were lower in the matrine group compared with the model group. The relative expression levels of Ki-67, proliferating cell nuclear antigen and Bax were decreased, while that of Bcl-2 was increased in the matrine group compared with the model group. In addition, the relative protein expression of nuclear factor $\kappa \mathrm{B}(\mathrm{NF}-\kappa \mathrm{B})$ in the matrine group was lower than that in the model group, but higher than that in the normal group. In summary, matrine inhibited activation of the $\mathrm{NF}-\kappa \mathrm{B}$ pathway and reduced cell proliferation and apoptosis in the oxLDL-induced atherosclerosis model, and exhibited anti-inflammatory effects. These results suggest that matrine attenuated abnormal biological reactions in HAVSMCs through the NF- $\kappa \mathrm{B}$ pathway.

\section{Introduction}

Atherosclerosis is the most common type of arteriosclerosis, which occurs in the subendothelial layer of the large and medium arteries, resulting in the blockage of blood flow triggered by endothelial dysfunction and the subendothelial retention of lipoproteins (1). Atherosclerosis is a key cause of mortality worldwide. In Western societies, it is the underlying cause of $\sim 50 \%$ of all mortality (2), and results in several medical complications, including myocardial infarction, stroke and peripheral arterial disease (3). A number of inflammatory biomarkers (including IL-6, IL-1 $\beta$, IL-10, TNF- $\alpha$, E-selectin, vascular cell adhesion molecule-1, adiponectin, high-sensitivity C-reactive protein and pentraxin 3) have been identified as independent risk factors for cardiovascular diseases, and studies have provided evidence for low-density lipoprotein (LDL)-induced immune activation in human atherosclerotic lesions (4). Numerous studies have been conducted with the aim of developing improved treatment strategies for atherosclerosis $(5,6)$.

Matrine is a key substance used in traditional Chinese medicine (7). It exerts anti-allergic, anti-inflammatory, antiviral and antifibrotic effects and is considered to be helpful for protecting against cardiovascular disease (8). The anti-inflammatory mechanism of matrine in microvascular endothelial cells has been shown to involve the increase of nitric 
oxide-dependent vasodilatation and the inhibition of lipopolysaccharide-induced inflammatory cytokines, indicating that matrine acts as a protective agent against inflammatory tissue damage (9). A previous study demonstrated that matrine was effective in treating liver cancer by inhibiting the expression of matrix metalloproteinase-9 and the invasion of human liver cancer cells, and further showed that the inhibitory effect was partly associated with downregulation of the nuclear factor- $\kappa \mathrm{B}$ $(\mathrm{NF}-\mathrm{\kappa} \mathrm{B})$ signaling pathway (10). In another study, matrine was shown to inhibit the invasion and metastasis of melanoma cells in vitro, and the induction of apoptosis was associated with the downregulation of heparinase mRNA and protein expression (11).

Based on these previous findings, we hypothesized that matrine may affect the inflammatory response and abnormal lipid metabolism of vascular smooth muscle cells, and aimed to investigate this and to elucidate the underlying mechanism in the present study.

\section{Materials and methods}

Cell culture and drug treatment. Human aortic vascular smooth muscle cells (HAVSMCs; Shenzhen Haodi Huatuo Biotechnology Co. Ltd.) were plated in 6-well plates and routinely cultured in high-glucose Dulbecco's modified Eagle's medium (Qingdao Jiesikang Biotechnology Co., Ltd.) containing $10 \%$ fetal bovine serum (Shanghai Xinfan Biotechnology Co., Ltd.) without antibiotics at $37^{\circ} \mathrm{C}$ in a $5 \% \mathrm{CO}_{2}$ incubator until they reached $60-70 \%$ confluency.

The proliferation of HAVSMCs treated with various concentrations $(0.0,0.5,1.0,2.0,4.0,6.0,8.0$ and $10.0 \mathrm{mg} /$ $\mathrm{ml}$ of matrine (Shanghai Yuanye Biotechnology Co., Ltd.) for 24 and $48 \mathrm{~h}$ was analyzed at $37^{\circ} \mathrm{C}$. In subsequent experiments, the cells were further assigned to normal, model and matrine groups. The model group was treated with $50 \mathrm{mg} / \mathrm{ml}$ oxidized LDL (oxLDL; Shanghai Lianmai Biological Engineering Co., Ltd.) to establish the atherosclerosis model. The matrine group was treated with $50 \mathrm{mg} / \mathrm{ml}$ oxLDL and $1.0 \mathrm{mg} /$ ml matrine. The normal group was treated with the same volume of normal saline. In the western blotting experiment, model + Bay11-7082 (NF-кB inhibitor, MedChemExpress, cat. no. HY-13453) and matrine + Bay11-7082 groups were also established by treatment with $2.5 \mu \mathrm{mol} / 1$ Bay11-7082 for $2 \mathrm{~h}$ at $37^{\circ} \mathrm{C}$. A flowchart of the study protocol is shown in Fig. 1.

Cell growth analysis. Cell proliferation in the normal, model and matrine groups was evaluated using a Cell Counting Kit-8 (CCK-8) assay kit (cat. no. ab228554; Abcam). A suspension of HAVSMCs was prepared and the $1 \times 10^{6}$ cell suspension (100 $\mu \mathrm{l})$ was added to each well of a 96 -well plate. Three replicates were prepared for each group and time point. Each well was treated with $20 \mu \mathrm{l}$ CCK-8 reagent after incubation for $24,48,72$ and $96 \mathrm{~h}$ at $37^{\circ} \mathrm{C}$ in a $5 \% \mathrm{CO}_{2}$ incubator. After incubation for $2 \mathrm{~h}$ with the CCK- 8 reagent, the absorbance at $490 \mathrm{~nm}$ was measured using an automated microplate reader. The experiment was repeated three times.

Analysis of lipid metabolism markers. Cell supernatants were collected from the normal, model and matrine groups and the levels of total cholesterol (TC; cat. no. JL19339), free cholesterol (FC; cat. no. JL20022) and cholesterol ester (CE; cat. no. JL19339) in the cell supernatants were determined using ELISA kits (Shanghai Jianglai Biological Technology Co., Ltd.) in accordance with the manufacturer's instructions. Experiments were repeated three times.

Detection of apoptotic rates. An apoptosis assay was performed on cells from the normal, model and matrine using an apoptosis kit according to the manufacturer's instructions (Apoptotic DNA-Ladder kit; Hangzhou Xinjing Biological Reagent Development Co., Ltd.). Flow cytometry (BD FACSCalibur; BD Pharmingen) was used to analyze the cells. The experiment was repeated three times.

Western blot analysis. Cells from the various treatment groups were lysed using radio-immunoprecipitation assay buffer (Beyotime Institute of Biotechnology). Protein determination by was performed via the BCA method and total protein was isolated. Equal amounts $(25 \mu \mathrm{g})$ total protein were separated on a $10 \%$ gel via sodium dodecyl sulfate polyacrylamide gel electrophoresis and transferred to a polyvinylidene difluoride (PVDF) membrane. The PVDF membrane was blocked with 5\% milk for $1 \mathrm{~h}$ at room temperature. The PVDF membrane was then washed with TBST (0.1\% Tween-20) three times The PVDF membrane was incubated with primary antibodies against Ki-67 (1:1,000; cat. no. ab15580; Abcam), proliferating cell nuclear antigen (PCNA; 1:1,000; cat. no. ab280088; Abcam), Bcl-2 (1:1,000; cat. no. ab32124; Abcam) and Bax (1:1,000; cat. no. ab182734; Abcam) at $4^{\circ} \mathrm{C}$ overnight. Secondary horseradish peroxidase (HRP)-rabbit antibody (1:5,000; cat. no. ab6858; Abcam) was then added to the membrane, after which it was incubated at room temperature for $2 \mathrm{~h}$. The PVDF membrane was then washed with TBST three times and developed using $5 \mathrm{ml}$ enhanced chemiluminescence substrate (Roche Diagnostics; cat. no. 11684817910) for 3 times and ImageJ software (version k 1.45; National Institutes of Health) was used for analysis.

Analysis of the mRNA expression of inflammatory factors. Total RNA was obtained from the cells using TRIzol ${ }^{\circledR}$ reagent (Thermo Fisher Scientific, Inc.), following the manufacturer's instructions. The concentration and purity of RNA were quantified using a UV spectrophotometer (Shanghai Qinxiang Scientific Instrument Co., Ltd.) by measuring the ratio of optical densities at 260 and $280 \mathrm{~nm}$, which were 1.8 and 2.0, respectively. cDNA was synthesized from the RNA by reverse transcription (RT) using reverse transcriptase (Shenzhen Zike Biotechnology Co., Ltd.) and oligonucleotides. The reaction mix contained (in $20 \mu \mathrm{l}$ volume): 1 dNTPs, 1 primers, 4 buffer, 2 reverse transcriptase, 2 total RNA and $12 \mu \mathrm{l}$ RNase-free water. The reaction conditions comprised incubation at $42^{\circ} \mathrm{C}$ in a water bath for $1 \mathrm{~h}$, followed by incubation at $95^{\circ} \mathrm{C}$ in a water bath for $5 \mathrm{~min}$. This was followed by quantitative PCR (qPCR) amplification using a Real-Time qPCR kit (Guangzhou Huafeng Biological Technology Co., Ltd.). Specific primers were used to detect the expression of interleukin (IL)-1 $\beta$, IL-6, tumor necrosis factor- $\alpha(\mathrm{TNF}-\alpha)$ and $\beta$-actin, which served as an internal 
Table I. Primer sequences.

\begin{tabular}{lll}
\hline Name & \multicolumn{1}{c}{ Forward (5'-3') } & \multicolumn{1}{c}{ Reverse $\left(5^{\prime}-3^{\prime}\right)$} \\
\hline IL-1 $\beta$ & CTTCAAATCTCACAGCAGCAGCATC & GCTGTCTAATGGGAACATCACA \\
IL-6 & GTTTGACCAGAGGACCCAGA & TCCTTTGTTACGGCTTCCAG \\
TNF- $\alpha$ & GTGCCTCAGCCTCTTCTCATT & CTCTGCTTGGTGGTTTGCTAC \\
$\beta$-actin & CACCCGCGAGTACAACCTTC & CCCATACCCACCATCACAAA
\end{tabular}

IL, interleukin; TNF, tumor necrosis factor.

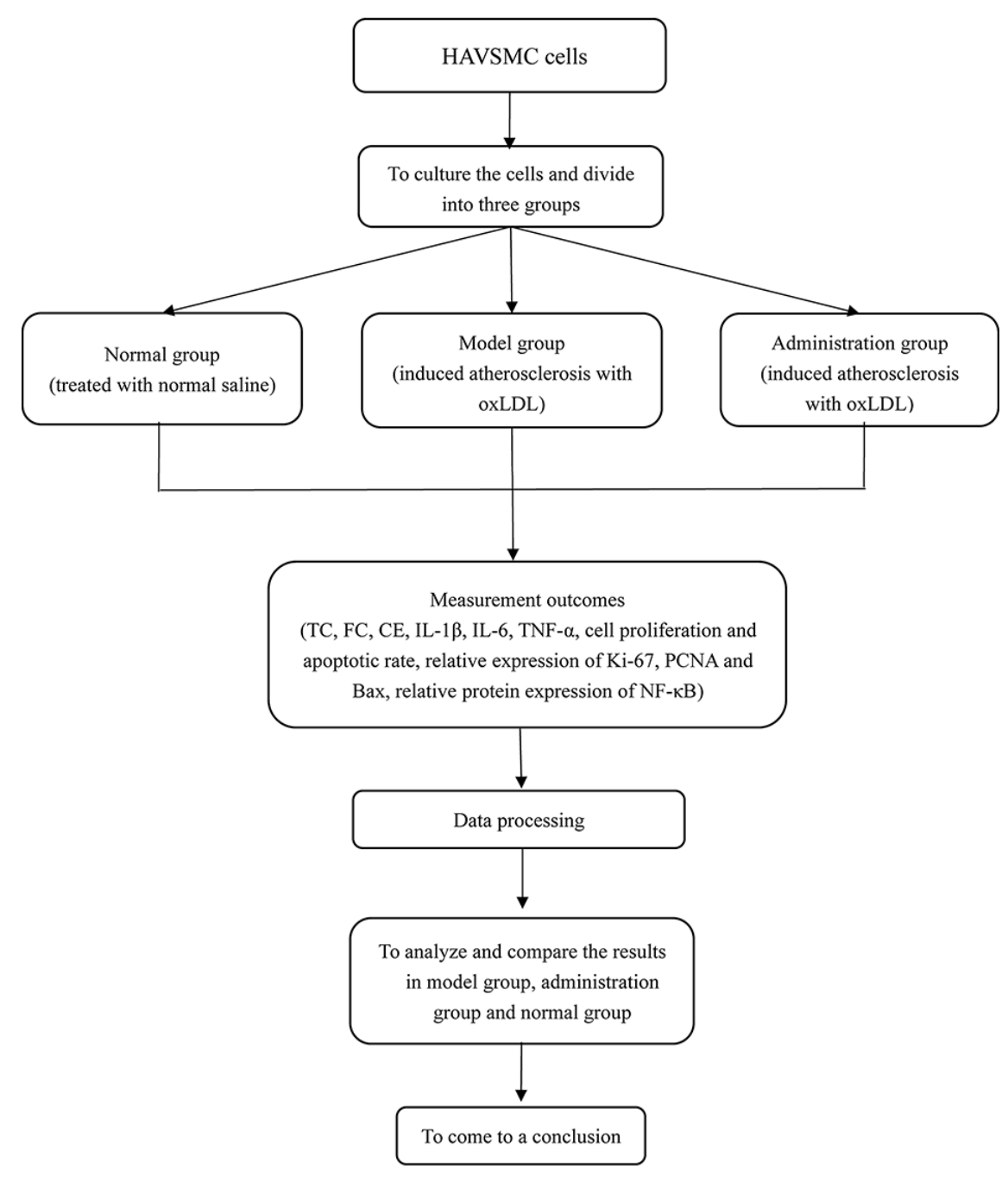

Figure 1. Flowchart of the study. HAVSMCs, human aortic vascular smooth muscle cells; oxLDL, oxidized low-density lipoprotein; TC, total cholesterol; FC, free cholesterol; CE, cholesterol ester; IL, interleukin; TNF, tumor necrosis factor; PCNA, proliferating cell nuclear antigen; NF- $\mathrm{BB}$, nuclear factor $\kappa \mathrm{B}$.

control. The qPCR reaction mixture $(20 \mu \mathrm{l})$ consisted of $0.4 \mu \mathrm{l}$ each of the upstream and downstream primers and $0.5 \mu 1$ Taq DNA polymerase diluted in $\mathrm{ddH}_{2} \mathrm{O}$. The conditions of the qPCR were as follows: $94^{\circ} \mathrm{C}$ for $10 \mathrm{sec}$, followed by 40 cycles of $94^{\circ} \mathrm{C}$ for $5 \mathrm{sec}, 52^{\circ} \mathrm{C}$ for $30 \mathrm{sec}$ and $72^{\circ} \mathrm{C}$ for $15 \mathrm{sec}$. All experiments were performed in triplicate and repeated three times. The results were analyzed using a relative quantitation method to internal controls; specifically, the expression levels of IL- $1 \beta$, IL- 6 and TNF- $\alpha$ were calculated using the $2^{-\Delta \Delta \mathrm{Cq}}$ method (12). The sequences of the primers used for the qPCR analysis of inflammatory factors and the internal controls (Suzhou Hongxun Biological Technology Co., Ltd.) are listed in Table I.

Statistical analysis. Statistical analysis was performed using SPSS 20.0 (IBM Corp.) statistical software. Data are expressed as the mean \pm standard deviation. One-way ANOVA with Tukey's post hoc test was used for the comparison of multiple groups. $\mathrm{P}<0.05$ was considered to indicate a statistically significant result. 


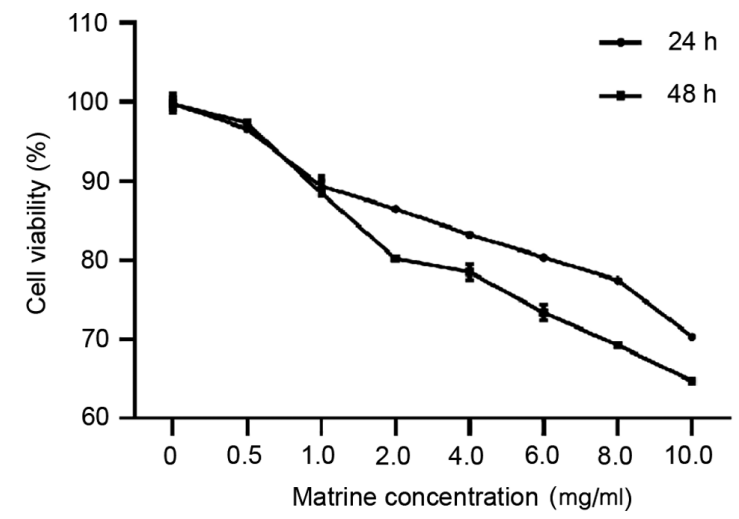

Figure 2. Selection of the optimum matrine concentration. Human aortic vascular smooth muscle cells were treated with $0.5-10 \mathrm{mg} / \mathrm{ml}$ matrine for 24 and $48 \mathrm{~h}$ and cell viability was then monitored using a Cell Counting Kit- 8 assay. Cell viability was $>90 \%$ at matrine concentrations $<1 \mathrm{mg} / \mathrm{ml}$ and was inversely proportional to the matrine concentration at concentrations $>1 \mathrm{mg} / \mathrm{ml}$.

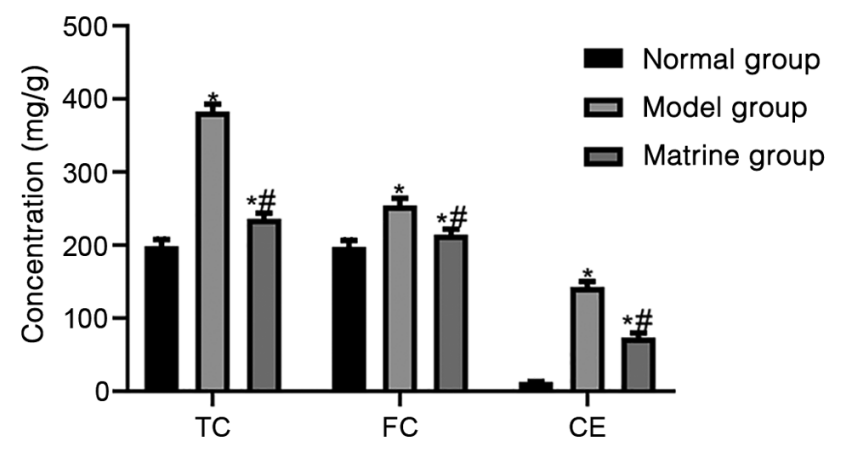

Figure 3. Effect of matrine on lipid metabolism in human aortic vascular smooth muscle cells treated with oxidized low-density lipoprotein. The levels of the lipid metabolism markers TC, FC and CE were analyzed in the normal, model and matrine groups. ${ }^{*} \mathrm{P}<0.05$ vs. the normal group; ${ }^{\#} \mathrm{P}<0.05$ vs. the model group. TC, total cholesterol; FC, free cholesterol; CE, cholesterol ester.

\section{Results}

Selection of the optimum concentration of matrine. The optimal matrine concentration was determined by treating HAVSMCs with $0.5-10 \mathrm{mg} / \mathrm{ml}$ matrine for 24 and $48 \mathrm{~h}$, and then analyzing the cell viability. The results of the CCK- 8 assay show that cell viability was $>90 \%$ for cells treated with $<1 \mathrm{mg} / \mathrm{ml}$ matrine, and for cells treated with matrine at concentrations $>1 \mathrm{mg} / \mathrm{ml}$, the cell viability was inversely proportional to the concentration. Thus, $1 \mathrm{mg} / \mathrm{ml}$ matrine was selected for subsequent experiments (Fig. 2).

Effect of matrine on lipid metabolism. The lipid metabolism markers TC, FC and CE were detected in the HAVSMCs in the normal, model and matrine groups. The levels of TC, FC and $\mathrm{CE}$ were $198.23 \pm 9.47,197.37 \pm 9.23$ and $12.48 \pm 0.58 \mathrm{mg} / \mathrm{g}$, respectively, in the normal group; $382.58 \pm 10.4,254.23 \pm 10.32$ and $142.67 \pm 7.35 \mathrm{mg} / \mathrm{g}$, respectively, in the model group; and $235.54 \pm 8.4,214.24 \pm 7.6$ and $73.24 \pm 6.54 \mathrm{mg} / \mathrm{g}$, respectively, in the matrine group. The results showed that the levels TC, FC and CE were significantly higher in the oxLDL-treated model group compared with the normal group $(\mathrm{P}<0.05)$. Furthermore,

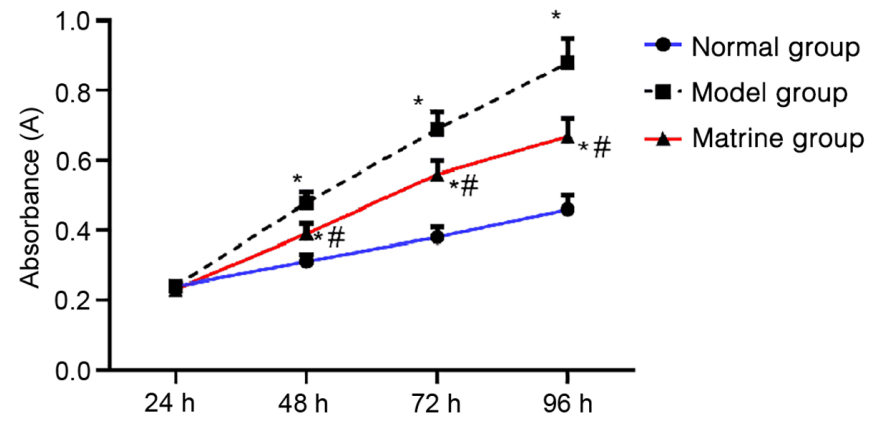

Figure 4. Effect of matrine on the growth of human aortic vascular smooth muscle cells treated with oxidized low-density lipoprotein. Cell proliferation in the normal, model and matrine groups was analyzed using a Cell Counting Kit- 8 assay. ${ }^{*} \mathrm{P}<0.05$ vs. the normal group; ${ }^{\#} \mathrm{P}<0.05$ vs. the model group.

the levels of TC, FC and CE in the matrine group were lower than those in the model group, although they remained higher than those in the normal group $(\mathrm{P}<0.05$; Fig. 3$)$

Effect of matrine on cell proliferation, apoptosis and associated proteins. From 48-96 h, cell growth was higher in the model and matrine groups compared with the normal group, and the cell growth in the matrine group was reduced compared with that in the model group $(\mathrm{P}<0.05)$. The cell growth in each group presented an upward trend over time (Fig. 4).

The apoptotic rates in the normal, model and matrine groups as determined using flow cytometry were $4.28 \pm 0.43$, $17.57 \pm 3.24$ and $7.59 \pm 2.52 \%$, respectively. These results indicate that the model group had an increased apoptosis rate compared with that of the normal group $(\mathrm{P}<0.05)$. Furthermore, the apoptosis rate of the matrine group was lower compared with that of the model, but higher than that of the normal group $(\mathrm{P}<0.05$; Fig. 5).

The expression of proliferation- and apoptosis-associated proteins was evaluated using western blotting. The relative expression levels of Ki-67, PCNA, Bcl-2 and Bax were $0.19 \pm 0.02,0.23 \pm 0.03,0.87 \pm 0.04$ and $0.16 \pm 0.01$, respectively, in the normal group; $0.86 \pm 0.05,0.82 \pm 0.04,0.27 \pm 0.02$ and $0.79 \pm 0.03$, respectively, in the model group; and $0.37 \pm 0.02$, $0.38 \pm 0.03,0.45 \pm 0.04$ and $0.33 \pm 0.03$, respectively, in the matrine group. In the model group, the expression levels of $\mathrm{Ki}-67, \mathrm{PCNA}$ and Bax were increased while those of Bcl-2 were decreased compared with those in the normal group $(\mathrm{P}<0.05)$. In addition, the matrine group showed decreased expression levels of Ki-67, PCNA and Bax and increased expression levels of Bcl-2 compared with those in the model group $(\mathrm{P}<0.05$; Fig. 6).

Matrine regulates cell proliferation and apoptosis through the $N F-\kappa B$ pathway. To further investigate the underlying mechanism of matrine, the expression of $\mathrm{NF}-\kappa \mathrm{B}$ was evaluated using western blotting. The relative protein expression levels of $\mathrm{NF}-\kappa \mathrm{B}$ in the normal, model and matrine groups were $0.27 \pm 0.04,0.71 \pm 0.05$ and $0.40 \pm 0.03$, respectively, indicating that the relative protein expression level of $\mathrm{NF}-\kappa \mathrm{B}$ in the model group was higher compared with that in the normal group $(\mathrm{P}<0.05)$. In the matrine group, the 


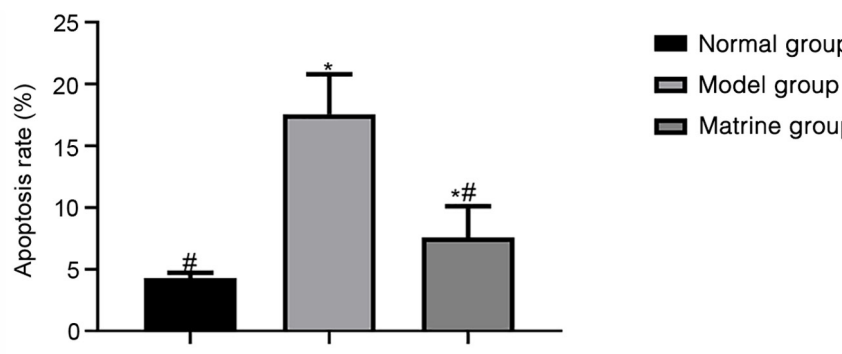

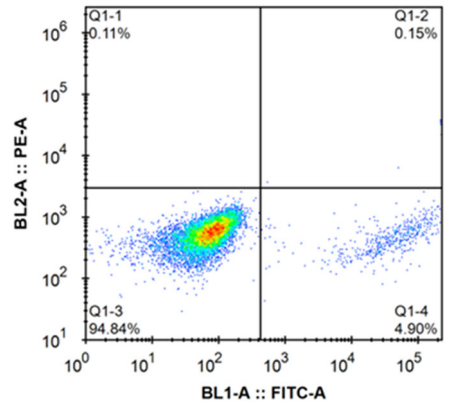

Normal group

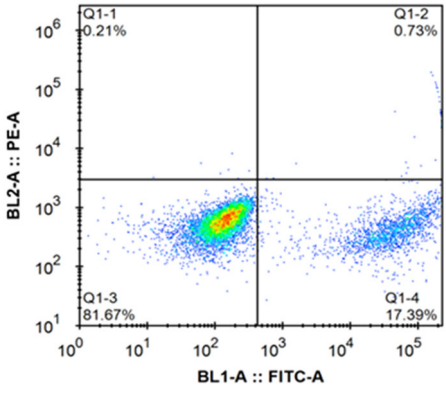

Model group

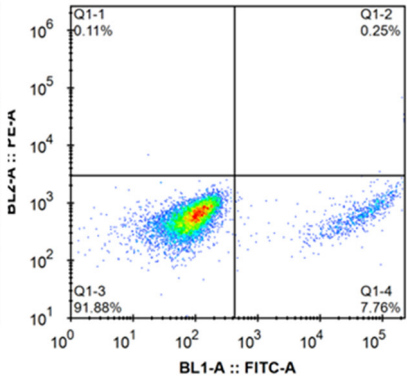

Matrine group

Figure 5. Effect of matrine on the apoptosis rate of human aortic vascular smooth muscle cells treated with oxidized low-density lipoprotein. The apoptotic rates in the normal, model and matrine groups were analyzed using flow cytometry. ${ }^{*} \mathrm{P}<0.05$ vs. the normal group; ${ }^{*} \mathrm{P}<0.05$ vs. the model group.
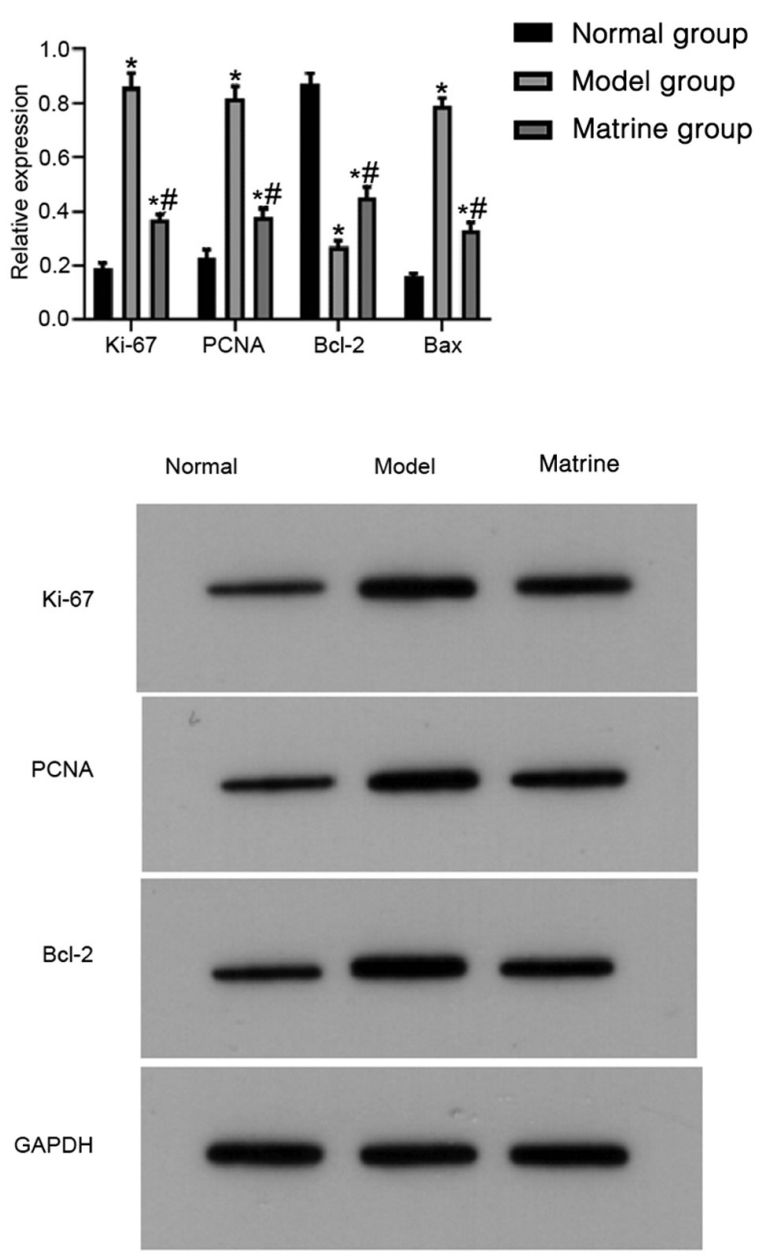

Figure 6. Effect of matrine on markers of cell proliferation and apoptosis in human aortic vascular smooth muscle cells treated with oxidized low-density lipoprotein. Relative expression levels of Ki-67, PCNA, Bcl-2 and Bax were analyzed in the normal, model and matrine groups by western blotting. "P<0.05 vs. the normal group; ${ }^{\text {P }}<0.05$ vs. the model group. PCNA, proliferating cell nuclear antigen.
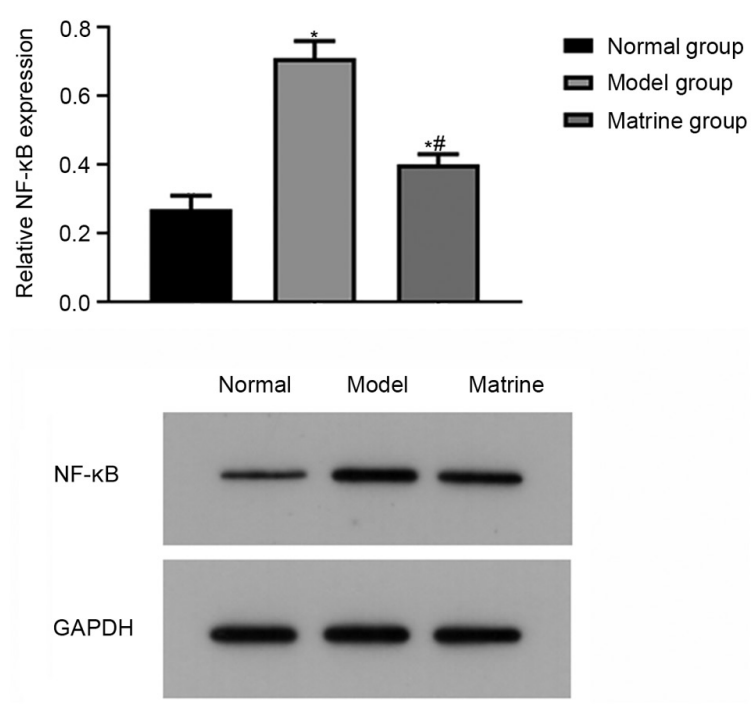

Figure 7. Effect of matrine on NF- $\mathrm{kB}$ expression in human aortic vascular smooth muscle cells treated with oxidized low-density lipoprotein. Relative expression levels of NF- $\mathrm{KB}$ in the normal, model and matrine groups were analyzed by western blotting. ${ }^{~} \mathrm{P}<0.05$ vs. the normal group; ${ }^{~} \mathrm{P}<0.05$ vs. the model group. NF- $\kappa \mathrm{B}$, nuclear factor $\kappa \mathrm{B}$.

relative expression of NF- $\mathrm{\kappa B}$ protein was lower than that in the model group but higher than that in the normal group $(\mathrm{P}<0.05$; Fig. 7).

After the analysis of the effects of modeling and matrine administration on the cells, additional groups, namely the model + Bay11-7082 group and matrine + Bay11-7082 group were established, and the effects of Bay11-7082 on the expression of proliferation- and apoptosis-associated proteins were assessed using western blotting. Consistent with the aforementioned results, compared with the normal group, the relative expression of $\mathrm{Ki}-67$, PCNA and Bax 

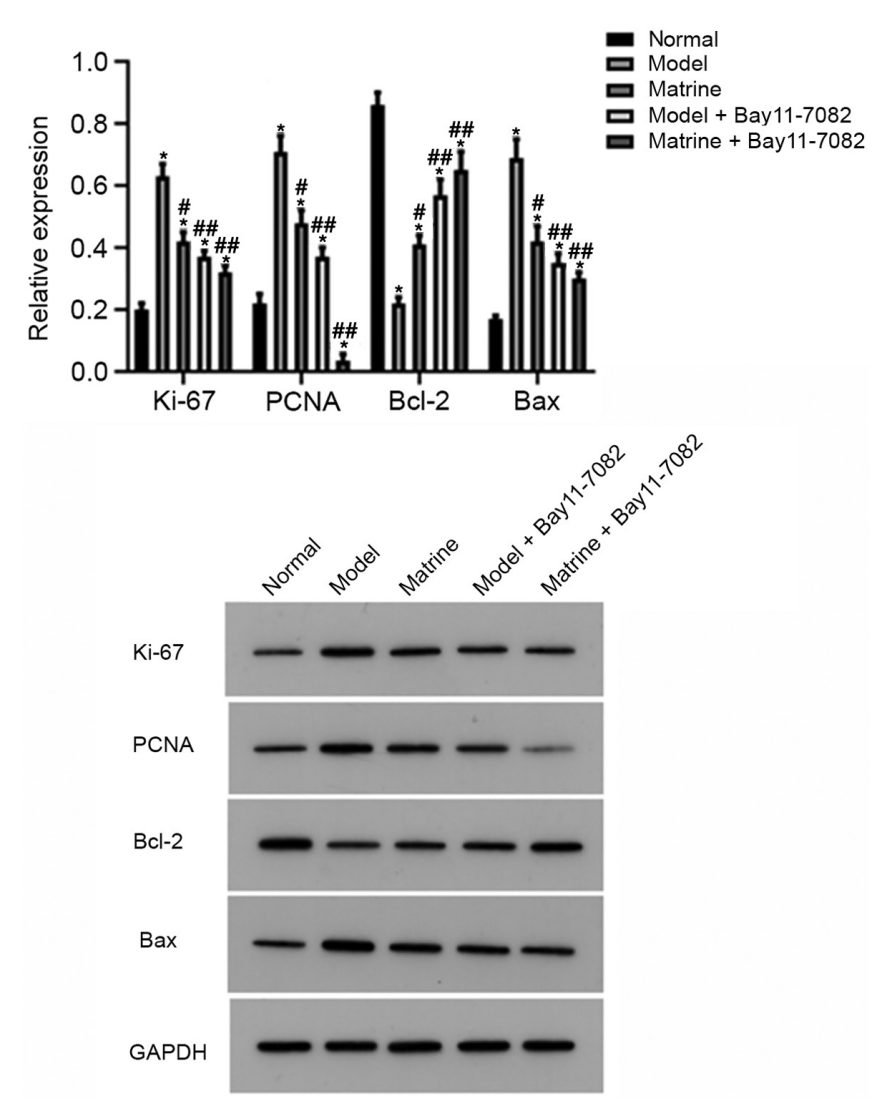

Figure 8. Matrine affects markers of cell proliferation and apoptosis through the NF-kB pathway. ${ }^{*} \mathrm{P}<0.05$ vs. the normal group; ${ }^{~} \mathrm{P}<0.05$ and ${ }^{\# \#} \mathrm{P}<0.01$ vs. the model group. NF- $\mathrm{\kappa B}$, nuclear factor $\kappa \mathrm{B}$.

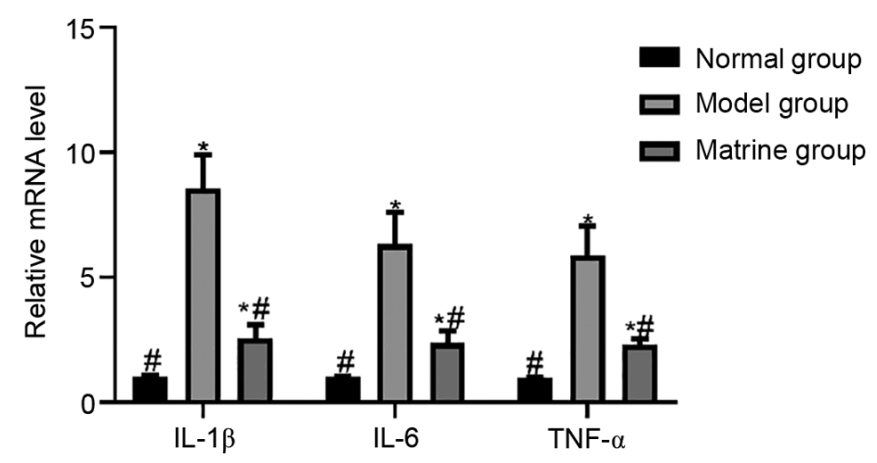

Figure 9. Effect of matrine on inflammatory factors in human aortic vascular smooth muscle cells treated with oxidized low-density lipoprotein. The relative mRNA levels of the inflammatory factors IL-1 $\beta$, IL- 6 and TNF- $\alpha$ were analyzed in the normal, model and matrine groups. ${ }^{*} \mathrm{P}<0.05$ vs. the normal group; ${ }^{\text {P }}<0.05$ vs. the model group.

increased in the model group, while that of $\mathrm{Bcl}-2$ decreased $(\mathrm{P}<0.05)$. However, the matrine, model + Bay11-7082 and matrine + Bay11-7082 groups exhibited lower relative expression levels of Ki-67, PCNA and Bax and higher relative expression levels of Bcl-2 compared with those in the model group $(\mathrm{P}<0.05$; Fig. 8$)$.

Matrine reduces inflammatory factors through the $N F-\kappa B$ pathway. The effect of matrine on oxLDL-induced inflammatory factors was assessed using RT-qPCR. The relative mRNA levels of IL-1 $\beta$, IL- 6 and TNF- $\alpha$ were $1.03 \pm 0.02,1.02 \pm 0.01$

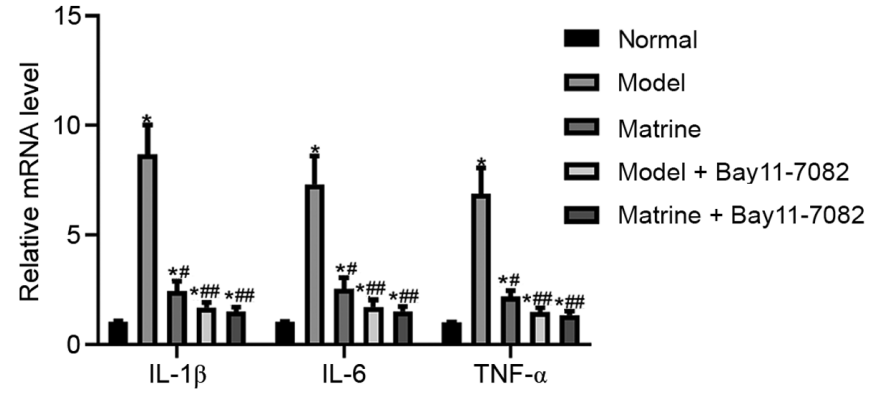

Figure 10. Matrine regulates the expression of inflammatory factors through the NF- $\kappa \mathrm{B}$ pathway. ${ }^{*} \mathrm{P}<0.05$ vs. the normal group; ${ }^{\#} \mathrm{P}<0.05$ and ${ }^{\# \#} \mathrm{P}<0.01$ vs. the model group.

and $0.99 \pm 0.01$, respectively, in the normal group; $8.57 \pm 1.34$, $6.32 \pm 1.29$ and $5.87 \pm 1.18$, respectively, in model group; and $2.57 \pm 0.54,2.38 \pm 0.48$ and $2.29 \pm 0.25$, respectively, in the matrine group. The results indicated that exposure to oxLDL in the model group significantly increased the relative mRNA levels of IL-1 $\beta$, IL- 6 and TNF- $\alpha$ compared with those in the normal group $(\mathrm{P}<0.05)$. The relative mRNA levels of IL-1 $\beta$, IL-6 and TNF- $\alpha$ in the matrine group were lower than those in the model group, but higher than those in the normal group $(\mathrm{P}<0.05$; Fig. 9).

The effect of Bay11-7082 on these inflammatory factors was also evaluated. As in the aforementioned results, the model group showed significantly upregulated mRNA levels of IL-1 $\beta$, IL- 6 and TNF- $\alpha$ compared with those in the normal group $(\mathrm{P}<0.05)$. However, the matrine, model + Bay11-7082 and matrine + Bay11-7082 groups exhibited lower mRNA levels of $1 \beta$, IL- 6 and TNF- $\alpha$ compared with those in the model group $(\mathrm{P}<0.05$; Fig. 10).

\section{Discussion}

Atherosclerosis is considered to be a chronic inflammatory disease of the vascular walls, while matrine has anti-inflammatory effects and also affects the cardiovascular system. Therefore, we hypothesized that matrine may have potential therapeutic use for preventing the progression of atherosclerotic lesions. Furthermore, exploration of the potential role and mechanism of matrine as an anti-atherosclerotic treatment may support research into the properties of traditional Chinese medicine and pharmacology. Inflammation is associated with the pathogenesis of atherosclerosis (13), and acts as a key regulatory process that links the risk factors for atherosclerosis (14). IL-1 $\beta$ is a key mediator of the host response to infection and inflammation (15). Although it helps in resisting pathogens, it also exacerbates damage during chronic diseases and acute tissue injury (16). A study suggested that IL-1 $\beta$ may play a local role in the formation and stability of atherosclerosis by inducing macrophages, endothelial cells and smooth muscle cells to produce cytokines and proteolytic enzymes (17). IL-6 is an inflammatory factor that plays a central role in the inflammatory response. It exists in cells and in extracellular deposits of connective tissue matrix in the human atherosclerotic wall and may be a crucial pro-atherosclerotic cytokine $(18,19)$. IL-6 has also been shown to be involved in the development of human atherosclerosis and is highly expressed in atherosclerosis (20). 
As a pro-inflammatory cytokine, $\mathrm{TNF}-\alpha$ is associated with metabolic disorders and may have a significant effect on the development of cardiovascular disease (21). The expression of TNF- $\alpha$ increases in atherosclerotic cardiovascular diseases (22). A previous study demonstrated that the administration of matrine to oxLDL-exposed macrophages reduced the protein and mRNA expression of inflammatory cytokines in a concentration-dependent manner (23). In the present study, the relative mRNA levels of IL-1 $\beta$, IL- 6 and TNF- $\alpha$ in the oxLDL-treated cell model were significantly higher than those in the normal group, but after treatment with matrine, the relative mRNA levels of IL-1 $\beta$, IL- 6 and TNF- $\alpha$ were significantly reduced. These results indicate that the expression levels of IL-1 $\beta$, IL-6 and TNF- $\alpha$ were increased under conditions simulating those of atherosclerosis, and matrine inhibited the expression of inflammatory cytokines.

As an acidic nuclear protein, PCNA is considered a histological marker of the $\mathrm{G}_{1} / \mathrm{S}$ phase in the cell cycle (24). Ki-67 and PCNA are two nuclear markers commonly used to signal the proliferation phase (25). Bcl-2 family proteins are the main regulators of cell cycle, and among them, Bax is pro-apoptotic, whereas Bcl-2 inhibits apoptosis (26). A previous study revealed the ability of matrine to inhibit and induce the differentiation of K-562 cells (27). In the present study, the results demonstrated that in the matrine group, the expression levels of Ki-67, PCNA and Bax were significantly decreased while those of Bcl-2 was increased compared with the respective levels in the model group. These results indicate that matrine inhibited the proliferation and apoptosis of vascular smooth muscle cells in this atherosclerotic model.

The NF- $\kappa \mathrm{B}$ pathway is well known as a typical pro-inflammatory signaling pathway (28), and $\mathrm{NF}-\kappa \mathrm{B}$ has been shown to regulate the expression of proteins that inhibit apoptosis and promote proliferation (29). In a previous study, matrine inhibited vascular cell adhesion molecule 1 and intercellular adhesion molecule 1 expression in TNF- $\alpha$-stimulated human aortic smooth muscle cells by inhibiting the production of reactive oxygen species and activating the $N F-\kappa B$ and MAPK pathways, which suggests its potential for the prevention of atherosclerosis (30). In the present study, whether matrine affected inflammatory factors and pro-apoptotic proteins through the $\mathrm{NF}-\kappa \mathrm{B}$ pathway was investigated. The results suggest that matrine may exert anti-inflammatory effects and inhibit cell proliferation by inhibiting activation of the NF- $\mathrm{BB}$ pathway. However, only cell experiments were performed, which limits the translational clinical value of the results.

In summary, the present study demonstrates that matrine attenuated the inflammatory response, abnormal lipid metabolism and proliferation of vascular smooth muscle cells exposed to oxLDL, and suggests that these effects were mediated via the $\mathrm{NF}-\kappa \mathrm{B}$ pathway.

\section{Acknowledgements}

Not applicable.

\section{Funding}

No funding was received.

\section{Availability of data and materials}

The datasets used and/or analyzed during the current study are available from the corresponding author on reasonable request.

\section{Authors' contributions}

GW and HW designed the experiments, CJ and CW carried out the experiments and ZL and AQ analyzed the experimental results. GW wrote the manuscript and $\mathrm{HW}$ revised the manuscript. GW and HW confirm the authenticity of all the raw data. All authors read and approved the final manuscript.

\section{Ethics approval and consent to participate}

Not applicable.

\section{Patient consent for publication}

Not applicable.

\section{Competing interests}

The authors declare that they have no competing interests.

\section{References}

1. Tabas I, García-Cardeña G and Owens GK: Recent insights into the cellular biology of atherosclerosis. J Cell Biol 209: 13-22, 2015.

2. Gisterå $\mathrm{A}$ and Hansson GK: The immunology of atherosclerosis. Nat Rev Nephrol 13: 368-380, 2017.

3. Feinberg MW and Moore KJ: MicroRNA regulation of atherosclerosis. Circ Res 118: 703-720, 2016.

4. Bäck M and Hansson GK: Anti-inflammatory therapies for atherosclerosis. Nat Rev Cardiol 12: 199-211, 2015.

5. Libby P and Everett BM: Novel antiatherosclerotic therapies. Arterioscler Thromb Vasc Biol 39: 538-545, 2019.

6. Zhu Y, Xian X, Wang Z, Bi Y, Chen Q, Han X, Tang D and Chen R: Research progress on the relationship between atherosclerosis and inflammation. Biomolecules 8: 80, 2018.

7. Zhang MJ and Huang J: Recent research progress of anti-tumor mechnism matrine. Zhongguo Zhong Yao Za Zhi 29: 115-118, 2004 (In Chinese).

8. Liu Y, Xu Y, Ji W, Li X, Sun B, Gao Q and Su C: Anti-tumor activities of matrine and oxymatrine: Literature review. Tumour Biol 35: 5111-5119, 2014.

9. Suo Z, Liu Y, Ferreri M, Zhang T, Liu Z, Mu X and Han B: Impact of matrine on inflammation related factors in rat intestinal microvascular endothelial cells. J Ethnopharmacol 125: 404-409, 2009.

10. Yu HB, Zhang HF, Li DY, Zhang X, Xue HZ and Zhao SH: Matrine inhibits matrix metalloproteinase-9 expression and invasion of human hepatocellular carcinoma cells. J Asian Nat Prod Res 13: 242-250, 2011.

11. Liu XY, Fang H, Yang ZG, Wang XY, Ruan LM, Fang DR, Ding YG, Wang YN, Zhang Y, Jiang XL and Chen HC: Matrine inhibits invasiveness and metastasis of human malignant melanoma cell line A375 in vitro. Int J Dermatol 47: 448-456, 2008.

12. Livak KJ and Schmittgen TD: Analysis of relative gene expression data using real-time quantitative PCR and the 2(-Delta Delta C(T)) method. Methods 25: 402-408, 2001.

13. de Boer OJ, van der Wal AC and Becker AE: Atherosclerosis, inflammation, and infection. J Pathol 190: 237-243, 2000.

14. Libby P, Ridker PM, Hansson GK and Leducq Transatlantic Network on Atherothrombosis: Inflammation in atherosclerosis: From pathophysiology to practice. J Am Coll Cardiol 54: 2129-2138, 2009. 
15. Faggioni R, Fantuzzi G, Fuller J, Dinarello CA, Feingold KR and Grunfeld C: IL-1beta mediates leptin induction during inflammation. Am J Physiol 274: R204-R208, 1998.

16. Lopez-Castejon $\mathrm{G}$ and Brough D: Understanding the mechanism of IL-1 $\beta$ secretion. Cytokine Growth Factor Rev 22: 189-195, 2011

17. Bhaskar V, Yin J, Mirza AM, Phan D, Vanegas S, Issafras H, Michelson K, Hunter JJ and Kantak SS: Monoclonal antibodies targeting IL-1 beta reduce biomarkers of atherosclerosis in vitro and inhibit atherosclerotic plaque formation in Apolipoprotein E-deficient mice. Atherosclerosis 216: 313-320, 2011.

18. Rus HG, Vlaicu R and Niculescu F: Interleukin-6 and interleukin- 8 protein and gene expression in human arterial atherosclerotic wall. Atherosclerosis 127: 263-271, 1996.

19. Stenvinkel P, Barany P, Heimbürger O, Pecoits-Filho R and Lindholm B: Mortality, malnutrition, and atherosclerosis in ESRD: What is the role of interleukin-6? Kidney Int Suppl: 103-108, 2002

20. Seino Y, Ikeda U, Ikeda M, Yamamoto K, Misawa Y, Hasegawa T Kano S and Shimada K: Interleukin 6 gene transcripts are expressed in human atherosclerotic lesions. Cytokine 6: 87-91, 1994.

21. Skoog T, Dichtl W, Boquist S, Skoglund-Andersson C, Karpe F, Tang R, Bond MG, de Faire U, Nilsson J,Eriksson P and Hamsten A: Plasma tumour necrosis factor-alpha and early carotid atherosclerosis in healthy middle-aged men. Eur Heart J 23: 376-383, 2002

22. Suarez EC, Lewis JG and Kuhn C: The relation of aggression, hostility, and anger to lipopolysaccharide-stimulated tumor necrosis factor (TNF)-alpha by blood monocytes from normal men. Brain Behav Immun 16: 675-684, 2002.
23. Zhou J, Ma W, Wang X, Liu H, Miao Y, Wang J, Du P, Chen Y, Zhang Y and Liu Z: Matrine suppresses reactive oxygen species (ROS)-mediated MKKs/p38-induced inflammation in oxidized low-density lipoprotein (ox-LDL)-stimulated macrophages. Med Sci Monit 25: 4130-4136, 2019.

24. Zhong W, Peng J, He H, Wu D, Han Z, Bi X and Dai Q: Ki-67 and PCNA expression in prostate cancer and benign prostatic hyperplasia. Clin Invest Med 31: E8-E15, 2008.

25. Kayaselçuk F, Zorludemir S, Gümürdühü D, Zeren $H$ and Erman T: PCNA and Ki-67 in central nervous system tumors: Correlation with the histological type and grade. J Neurooncol 57: 115-121, 2002.

26. Reed JC: Proapoptotic multidomain Bcl-2/Bax-family proteins: Mechanisms, physiological roles, and therapeutic opportunities. Cell Death Differ 13: 1378-1386, 2006.

27. Zhang LP, Jiang JK, Tam JW, Zhang Y, Liu XS, Xu XR, Liu BZ and $\mathrm{He}$ YJ: Effects of matrine on proliferation and differentiation in K-562 cells. Leuk Res 25: 793-800, 2001.

28. Lawrence T: The nuclear factor NF-kappaB pathway in inflammation. Cold Spring Harb Perspect Biol 1: a001651, 2009.

29. Moynagh PN: The NF-kappaB pathway. J Cell Sci 118: 4589-4592, 2005.

30. Liu J, Zhang L, Ren Y, Gao Y, Kang L and Lu S: Matrine inhibits the expression of adhesion molecules in activated vascular smooth muscle cells. Mol Med Rep 13: 2313-2319, 2016.

This work is licensed under a Creative Commons

Attribution-NonCommercial-NoDerivatives 4.0 International (CC BY-NC-ND 4.0) License. 